\title{
An Effect of Bilingualism on the Auditory Cortex
}

\author{
Volker Ressel, ${ }^{1}$ Christophe Pallier, ${ }^{2}$ Noelia Ventura-Campos, ${ }^{3}$ Begoña Díaz, ${ }^{4}$ Abeba Roessler, ${ }^{1}$ César Ávila, ${ }^{3}$ \\ and Núria Sebastián-Gallés ${ }^{1}$ \\ ${ }^{1}$ Speech Acquisition and Perception Group, Center for Brain and Cognition, Department of Technology, Pompeu Fabra University, 08018 Barcelona, Spain, \\ 2INSERM, CEA, Cognitive Neuroimaging Unit, Neurospin Center, F-91191 Paris, France, ${ }^{3}$ Department of Psychology, Jaume I University, 12071 Castellón \\ de la Plana, Spain, and ${ }^{4}$ Max Planck Institute for Human Cognitive and Brain Sciences, 04103 Leipzig, Germany
}

Two studies (Golestani et al., 2007; Wong et al., 2008) have reported a positive correlation between the ability to perceive foreign speech sounds and the volume of Heschl's gyrus (HG), the structure that houses the auditory cortex. More precisely, participants with larger left Heschl's gyri learned consonantal or tonal contrasts faster than those with smaller HG. These studies leave open the question of the impact of experience on HG volumes. In the current research, we investigated the effect of early language exposure on Heschl's gyrus by comparing Spanish-Catalan bilinguals who have been exposed to two languages since childhood, to a group of Spanish monolinguals matched in education, socio-economic status, and musical experience. Manual volumetric measurements of HG revealed that bilinguals have, on average, larger Heschl's gyri than monolinguals. This was corroborated, for the left Heschl's gyrus, by a voxel-based morphometry analysis showing larger gray matter volumes in bilinguals than in monolinguals. Since the bilinguals in this study were not a self-selected group, this observation provides a clear demonstration that learning a second language is a causal factor in the increased size of the auditory cortex.

\section{Introduction}

The brain's shape and volume vary considerably between individuals (Ono et al., 1990). Genetic, environmental, and experience-dependent factors all play a role (Golestani et al., 2011; Yoon et al., 2011). In two studies of experience-dependent brain plasticity, Maguire et al. (2000) reported that the size of the hippocampus correlated positively with years of professional practice in taxi drivers, and Draganski et al. (2004) observed increased gray matter (GM) density in the mid-temporal area after juggling training. More recently, Abdul-Kareem et al. (2011) reported a correlation between GM volume in Broca's area and years of musical performance in musicians and Carreiras et al. (2009) showed structural brain differences between literates and illiterates.

Concerning the auditory cortex, it is known that deafness or tinnitus can have a negative impact on its development (Emmorey et al., 2003; Schneider et al., 2009). Additionally, an enriched environment, such as musical education, can lead to enlargement of the Heschl's gyrus (HG) (Schneider et al., 2002). One can wonder whether language experience also plays a role. Very little

Received April 24, 2012; revised Sept. 17, 2012; accepted Sept. 28, 2012.

Author contributions: V.R., C.P., B.D., C.Á., and N.S.-G. designed research; V.R. and N.V.-C. performed research; V.R., C.P., N.V.-C., A.R., and C.Á. analyzed data; V.R., C.P., B.D., C.Á., and N.S.-G. wrote the paper.

This work was supported by grants from the Spanish Ministerio de Ciencia e Innovación (JCl-2009-04492, PSI2010-20168; SEJ2009-09072, Consolider-Ingenio2010-CDS-2007-00012), the Catalan Government (SGR 20091521), and the French National Agency for Research (ANR 2010 BLAN 1403 01). N.S.-G. received the prize ICREA Acadèmia for excellence in research, funded by the Generalitat de Catalunya. We thank Kimberly Brink for the English correction of the manuscript.

The authors declare no competing financial interests.

Correspondence should be addressed to Dr. Christophe Pallier, INSERM, CEA, Cognitive Neuroimaging Unit, Neurospin Center, F-91191 Paris, France. E-mail: christophe@pallier.org.

DOI:10.1523/JNEUROSCI.1996-12.2012

Copyright $\odot 2012$ the authors $\quad 0270-6474 / 12 / 3216597-05 \$ 15.00 / 0$ research exists on that question. A first attempt was made by Kochunov et al. (2003), who compared English and Chinese speakers and reported differences of several brain areas. However, because the Chinese speakers in this study were Asians born in China and the English speakers were Caucasians born in the United States, the linguistic contrast was confounded with ethnic and cultural differences. More recently, Crinion et al. (2009) compared Chinese and English speakers, controlling for ethnicity, and reported higher GM and white matter (WM) densities in the right anterior temporal lobe and the left posterior insula of the Chinese speakers. The authors propose that this may be the result of training to process linguistic tones.

A last hint that language experience can affect languagerelated brain development comes from Mechelli et al. (2004), who compared bilingual to monolingual speakers. Using voxelbased morphometry (VBM) analyses, they observed that the mastery of a second language correlated with higher GM density in the left posterior inferior parietal cortex, a region involved in vocabulary acquisition (see also Lee et al., 2007).

Bilinguals not only have to master two lexicons but also two phonological systems. This begs the question of whether the parts of the brain supporting phonetic/phonological processes, in the auditory cortex and its immediate vicinity (Jacquemot et al., 2003), differ between bilinguals and monolinguals. The two studies mentioned in the abstract (Golestani et al., 2007 and Wong et al., 2008) have reported a positive correlation between the volume of HG and the ability to perceive foreign speech sounds or tones (see also Sutherland et al., 2012). But it is unknown whether these differences in HG's volume were innate or due to experience. Mechelli et al.'s (2004) study comparing bilinguals to monolinguals did not report any difference between the two groups in the auditory cortex, but their whole-brain approach 
Table 1. Spanish-Catalan bilingual participants' linguistic background

\begin{tabular}{lcccc}
\hline Variable & Minimum & Maximum & Mean & SD \\
\hline Onset of listening to Catalan (years) & 0 & $6^{a}$ & 1.1 & 1.9 \\
Onset of speaking Catalan (years) & 0 & $7^{a}$ & 2.2 & 2.1 \\
Onset of listening to Spanish (years) & 0 & $6^{a}$ & 1.2 & 1.9 \\
Onset of speaking Spanish (years) & 0 & $6^{a}$ & 2.4 & 2.0 \\
Pronunciation score in Catalan (1-4) & 1 & 3 & 1.1 & 0.5 \\
Pronunciation score in Spanish (1-4) & 1 & 2 & 1.2 & 0.4 \\
Proportion listening to Catalan (\%) & 20 & 80 & 46.1 & 18.6 \\
Proportion speaking Catalan (\%) & 10 & 90 & 57.5 & 24.1 \\
\hline
\end{tabular}

The fluency scores used a four-point scale ( $1=$ perfect, $2=$ good, $3=$ sufficient, $4=$ poor).

${ }^{a}$ All participants, except two (who started between $5-7$ years of age), started to listen and talk both languages before 3 years of age.

may have lacked sufficient sensitivity. Therefore, we decided to directly measure the size of auditory cortices in matched groups of bilinguals and monolinguals.

\section{Materials and Methods}

Participants. Forty-four right-handed participants, students at the University Jaume I of Castellón de la Plana (Spain), with no known auditory or neurological deficits, took part in the study. Twenty-two were monolingual Spanish speakers (11 women; mean age $=23.1$.years, $S D=4.75$ years) and 22 were highly fluent Catalan-Spanish bilinguals (11 women; mean age $=21.5$ years, $\mathrm{SD}=2.7$ years). The study followed the ethical protocol of the University Jaume I of Castellón and all the participants were paid for their participation.

The monolinguals had been exposed to Catalan for 3 months at most, since their arrival in Castellon; the bilingual participants had learned both Catalan and Spanish before the age of 7 years and used them daily (for information about their linguistic background, see Table 1). As the participants had received formal education in English or French in school, starting at age 8.9 years $(\mathrm{SD}=3.5$ years), we asked them to self-rate their comprehension, reading, fluency, pronunciation, and writing skills in French and in English (on a four-point scale: 1 = perfect, $2=$ good, 3 = sufficient, $4=$ poor). The scores showed that no participant had a much proficiency in any of these languages (range of average ratings: 2.4-3.9). Both groups of participants reported a poor command of French (average ratings: bilinguals: $3.7, \mathrm{SD}=0.6$; monolinguals: 3.9, $\mathrm{SD}=0.3 ; t_{(42)}=1.4$ ) and a moderate command of English (bilinguals' scores were higher than monolinguals'; average ratings: 2.7 and $3.3, \mathrm{SD}=$ 0.3 and 0.25 , respectively; $t_{(42)}=3.4 p<0.05$ ).

Finally, information about participants' musical education was collected over the phone or through e-mail a few months after the scanning session. Four participants ( 2 bilinguals and 2 monolinguals) could not be contacted a posteriori. The following questions were asked: Have you ever played an instrument? When did you start? For how many years did you play? How many hours per week do you currently play an instrument? Additional information about attendance, starting age, and years spent in a music school was collected. The groups did not significantly differ in musical expertise.

Image acquisition and processing. Structural MRI data were acquired with a 1.5-T Siemens Avanto. Participants' heads were immobilized with cushions to reduce motion artifacts. The $3 \mathrm{D}$ anatomical volumes were acquired using a T1-weighted gradient echo pulse sequence $(\mathrm{TR} / \mathrm{TE}=$ $11 / 4.9$ ms, matrix $=256 \times 224 \times 176$; voxel size $=1 \times 1 \times 1 \mathrm{~mm})$.

Segmentation of Heschl's gyri. The anatomical images were spatially normalized (affine registration only) onto the Montreal Neurological Institute MNI152 template using SPM5 (The Wellcome Department of Imaging Neuroscience, London, UK).

Hesch's gyri were then manually segmented on the anatomically normalized images using Anatomist software (http://brainvisa.info), displaying sagittal, axial, and coronal planes simultaneously. Each HG was first identified in the axial plane following the procedure described in Penhune et al. (1996). The HG was delimited with a line from the medial end of the first transverse sulcus to the medial end of the Heschl sulcus. The inferior boundary of the HG was identified in the sagittal and coro- nal planes with a line from the depth of the Heschl sulcus to the first transverse sulcus in the stem of the HG. The superior boundary was defined in the coronal and sagittal planes by the visible ending of the HG. However, multiple or split HG are frequently present. It has been shown that primary auditory areas are located in the most anterior gyri whenever there are multiple transverse gyri (Rademacher et al., 2001). In the case of split HG (at least half of its length), the primary auditory areas may also be located in the most anterior gyral subregion (Rademacher et al., 2001). Therefore, when multiplications of HG or split HG were present, only the most anterior gyri or gyral subregion was segmented. Two trained raters manually drew the HG. They were blind to group (monolinguals and bilinguals), gender, and hemisphere (left and right). The volumes of HG were calculated from the number of voxels in the manually drawn masks. Moreover, the masks were intersected with individual segmented white and gray matter images computed by SPM5 to provide volumes of white and gray matter, respectively. Finally, an inverse normalization was performed on the HG mask to compute the volumes in the native space. Inter-rater reliability was assessed by comparing the global volumes of all HG. The Pearson's $r$ correlation between the volumes measured by the two raters was $0.87(n=88, p<0.001)$.

Voxel-based morphometry analysis. VBM was performed using the Diffeomorphic Anatomical Registration through Exponentiated Lie algebra toolbox (DARTEL) procedure implemented in SPM8 (Ashburner, 2007; http://www.fil.ion.ucl.ac.uk/spm). The MR images were segmented into GM, WM, and CSF using the standard unified segmentation model in SPM8 (Ashburner and Friston, 2005). The clean-up procedure was applied to the segmented GM images to remove nonbrain tissue. The GM and WM segmented images were normalized, respectively, to the GM and WM population templates generated from our complete database image set (200 subjects) using the DARTEL registration method (Ashburner, 2007). This template is an affine registration in MNI fields. Individual images were normalized to the template, keeping a voxel resolution of $1 \times 1 \times 1 \mathrm{~mm}$. Spatially normalized images were modulated to ensure that the overall amount of each tissue class was not altered by the spatial normalization procedure, thus allowing the comparison of volume differences. Finally, the images were smoothed with an $8 \mathrm{~mm}$ full-width at half-maximum Gaussian kernel. The statistical analyses were performed using SPM8, with linear models that included, beside the main variable Group (Monolingual vs Bilinguals), whole-brain volumes (sum of GM and WM volumes computed by SPM) and gender as covariates.

\section{Results}

Figure 1 shows the distributions of individual measurements of HG volumes in the normalized space. Bilinguals had, on average, larger HG than monolinguals, both in the left and in the right hemisphere. This was confirmed by an ANOVA with the factors Group (Monolinguals vs Bilinguals), Gender (Male vs Female), and Side (Left vs Right), in which the effects of Group (Bilinguals $>$ Monolinguals; $\left.F_{(1,40)}=5.4 ; p<0.05\right)$ and Gender $(\mathrm{Fe}-$ male $>$ Male; $\left.F_{(1,40)}=5.8 ; p<0.05\right)$ were significant.

The difference between the bilinguals and monolinguals was also observed for measurements in native space (NS), and for normalized GM and WM volumes. The GM measurement showed a Group (Bilinguals $>$ Monolinguals; $F_{(1,40)}=5.5 ; p<$ 0.05 ) and Gender (Female $>$ Male; $F_{(1,40)}=7.1 ; p<0.05$ ) effect without interaction. The WM and NS measurements only showed a significant Group effect (Bilinguals $>$ Monolinguals; WM: $F_{(1,40)}=4.5, p<0.05$; NS: $\left.F_{(1,40)}=7.5, p<0.01\right)$.

Table 2 displays the gross morphological features of HG (single, split, duplicate, or triple gyri) for the two groups. There is a trend toward more frequent split HG in monolinguals compared with bilinguals, although this result is not significant (Fisher's exact test: left HG: $p=0.30$; right HG: $p=0.21$ ).

No significant differences in the normalized HG volumes were found between participants playing an instrument and those who reported not to play any (for all $t$ tests, $p>0.05$ ). Also, no signif- 

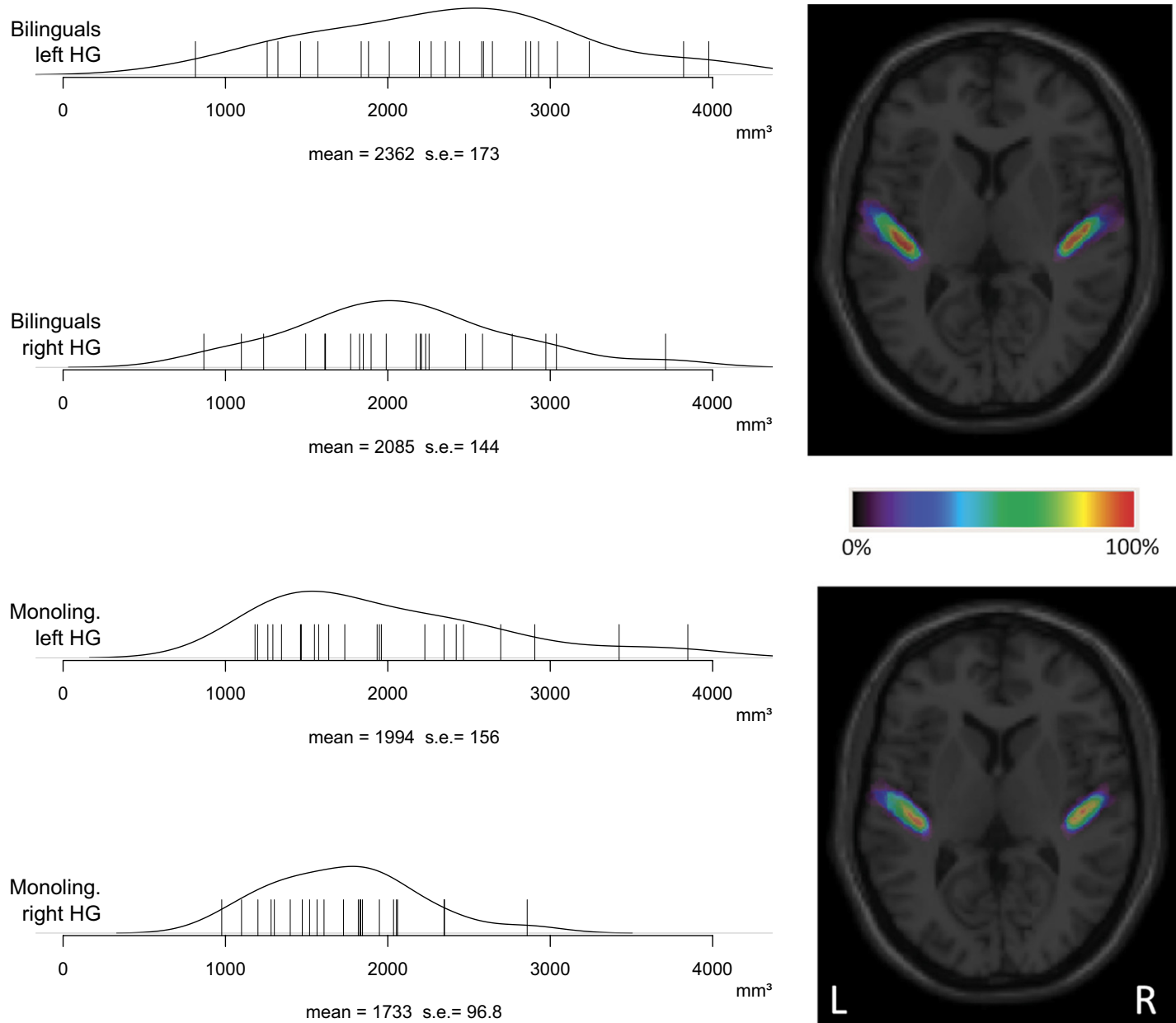

Figure 1. Distributions of individual Heschl's gyri volumes. Heschl's gyrus volumes (in $\mathrm{mm}^{3}$; normalized space) as a function of Side (left vs right hemisphere) and Group (monolingual vs bilingual). Left, Each line represents one Heschl's gyrus for each participant. The distribution of the volumes, the mean, and the SE are shown. Right, Probability maps of Heschl's gyrus.

Table 2. Gross morphological features of HG (single, split, duplicate, or triple gyri)

\begin{tabular}{lcccc}
\hline & Single & Split & Duplicate & Triple \\
\hline $\begin{array}{l}\text { Left hemisphere } \\
\text { Monolinguals }\end{array}$ & 6 & 12 & 4 & \\
$\begin{array}{l}\text { Bilinguals } \\
\text { Right hemisphere }\end{array}$ & 11 & 9 & 2 & 0 \\
Monolinguals & 9 & 7 & 4 & 2 \\
Bilinguals & 15 & 4 & 3 & 0 \\
\hline
\end{tabular}

icant differences were found between participants who had attended a music school and those who had not (for more information, see Table 3). Additionally, no significant correlation between HG volumes and the variables onset of playing, years of playing, or hours per week of playing were observed.

Regarding English and French as a foreign language, no significant correlation between HG volumes and self-reported language scores were seen.

The VBM analysis comparing gray matter between bilinguals and monolinguals (and including whole-brain volume and gender as covariates) did not detect significant differences at the threshold $t=5.22[p<0.05$, family-wise error (FWE) corrected for multiple comparisons], but at a lower threshold of $t=3.3$ $(p<0.001$ voxel-based, uncorrected), differences (Bilinguals $>$ Monolinguals) were detected in the left HG (MNI coordinates: $x=-52, y=-13, z=5 ; t=3.52$; cluster size $\left.=65 \mathrm{~mm}^{3}\right)$ and in the right anterior/middle cingulum (MNI coordinates: $x=9, y=$
Table 3. Normalized Heschl's gyrus volumes (in $\mathrm{mm}^{3}$, means and SD) as a function of musical education

\begin{tabular}{llcll}
\hline Musical education & YES/NO & Bilingual/Monolingual & Left HG & Right HG \\
\hline Instrument & YES $(n=20)$ & Bilingual $(n=13)$ & $2473(857)$ & $2219(720)$ \\
& & Monolingual $(n=7)$ & $2132(1101)$ & $1536(421)$ \\
& NO $(n=20)$ & Bilingual $(n=7)$ & $2336(769)$ & $1994(502)$ \\
& & Monolingual $(n=13)$ & $1948(567)$ & $1776(354)$ \\
Musical school & YES $(n=15)$ & Bilingual $(n=9)$ & $2516(739)$ & $2200(623)$ \\
& & Monolingual $(n=6)$ & $1841(864)$ & $1480(394)$ \\
& NO $(n=25)$ & Bilingual $(n=11)$ & $2352(892)$ & $2092(693)$ \\
& & Monolingual $(n=14)$ & $2085(749)$ & $1796(348)$ \\
\hline
\end{tabular}

$n=40$, as four participants from the original group could not be contacted for the post hoc interview.

$-1, z=38 ; t=4.69$; cluster size $=649 \mathrm{~mm}^{3}$ ). The inverse contrast Monolinguals $>$ Bilinguals did not yield any difference even at the $p<0.001$ uncorrected level. Restricting the analysis (using small volume correction) within the left and right HG areas defined from the toolbox WFU Pickatlas 2.5.2 (Maldjian et al., 2003) yielded significant group differences [ $p$ FWE corrected for multiple comparisons $\left.\left(p_{\mathrm{FWE}-\mathrm{corr}}\right)<0.05\right]$ in GM volume in the left HG (MNI coordinates: $x=-52, y=-13, z=6 ; t=3.52$; cluster size $\left.=41 \mathrm{~mm}^{3} ; p_{\text {FWE-corr }}=0.02\right)$. No significant differences were observed between bilinguals and monolinguals in similar analyses of white matter. The inverse contrast Monolinguals $>$ Bilinguals did not yield any significant difference. The inclusion of gross morphologies of left and right Heschl gyri 
(coding: $1=$ single, $1.5=$ split, $2=$ duplicate, $3=$ triple) as additional covariates did not alter these results (MNI coordinates: $x=-52, y=-13, z=6$; $t=3.48$; cluster size $=33 \mathrm{~mm}^{3}$; $\left.p_{\text {FWE-corr }}=0.03\right)$.

\section{Discussion}

In the present study, we investigated the influence of early language exposure on brain morphology. We found significantly larger HG volumes in bilinguals compared with monolingual participants. This was true both for gray and white matter volumes, for both hemispheres, and for measurements in native and normalized spaces. These results are worth comparing with previous studies looking at effects of language-training experience (Golestani et al., 2011) and language learning (Crinion et al., 2009).

Golestani et al. (2011), comparing expert phoneticians to controls, reported differences in HG morphology and in the size of the pars opercularis. Yet, the effect of years of practice was only observed in the pars opercularis. The authors argue that HG morphology (especially gyrification) cannot be modified by linguistic experience or training in adulthood (Golestani et al., 2011). Here, we found that early linguistic experience (being a bilingual or a monolingual) had an impact on the volumes of HG. We also observed a trend for more splitting of HG in monolinguals than in bilinguals that could reflect early experience-dependent plasticity. It remains an open question whether similar patterns could be found between late second-language learners and monolinguals.

Language characteristics can also influence brain morphology. Crinion et al. (2009) have shown structural differences in bilingual and monolingual speakers of Chinese and English, studying differences in brain morphology due to expertise. They were especially interested in identifying differences in pitch perception and production of these two languages of tonal (Chinese) and nontonal (English) nature. The results of the study showed an increase in gray and white matter in the right temporal lobe and left insula in those subjects who spoke Chinese compared with those who did not. Both groups, native Chinese and European subjects who learned Chinese as a second language, showed this effect, discarding an ethnicity bias. Similar to Crinion et al. (2009), in our study we were interested in brain morphological differences due to expertise controlling for an effect of ethnicity. Additionally, we controlled for language characteristics. We tested participants from Spain who were monolingual (Spanish) or bilingual (Spanish and Catalan). Here it is important to mention that both languages in our study are not tonal and are typologically closely related, which gives additional information on brain differences with respect to language characteristics. We suggest that our results show a clear difference in HG volumes between monolinguals and bilinguals, which can be related to lifelong expertise in language (monolingual/bilingual) and eliminates other factors like language characteristics in pitch perception (tonal/nontonal), ethnicity, or late second language learning.

As mentioned in the introduction and closer to the present study, Mechelli et al. (2004) compared bilinguals (first language: English, second language: other European language) to monolinguals using VBM and observed an increase in gray matter density in a posterior inferior parietal region that, they suggested, might be linked to vocabulary acquisition (Lee et al., 2007). A similar VBM analysis performed on our participants' scans did not detect a difference in the parietal region but confirmed the HG difference. Such a discrepancy could result from the specific similari- ties and differences between Spanish and Catalan. Catalan and Spanish overlap significantly at the lexical level but differ in phonology; therefore, it is likely that Spanish-Catalan bilinguals need to recruit regions close to the $\mathrm{HG}$, related to the processing of phonological information (Jacquemot et al., 2003). It is important to note that both the VBM analyses and our direct measurements of HG cannot precisely target the primary auditory cortex (Rademacher et al., 2001). Therefore, we do not imply that bilinguals versus monolinguals differences are restricted to the primary auditory cortex. Beside HG, at a lower, uncorrected, statistical threshold, differences in GM are also observed in the right cingulate cortex, which has been implicated in language switching (Wang et al., 2007; Abutalebi et al., 2012).

The bilinguals in our study were early and highly skilled bilinguals; that is, they had acquired both languages in childhood and lived all their lives in a fully bilingual society. Because the two groups were not self-selected; that is, the bilinguals did not become bilinguals because they were specially gifted at learning foreign languages, one can conclude that the learning of a second language is most likely a causal factor in the increased size of the auditory cortex. It remains to be determined whether late learning, for example in adulthood, can lead to the same increase.

\section{References}

Abdul-Kareem IA, Stancak A, Parkes LM, Sluming V (2011) Increased gray matter volume of left pars opercularis in male orchestral musicians correlate positively with years of musical performance. J Magn Reson Imaging 33:24-32. CrossRef Medline

Abutalebi J, Della Rosa PA, Green DW, Hernandez M, Scifo P, Keim R, Cappa SF, Costa A (2012) Bilingualism tunes the anterior cingulate cortex for conflict monitoring. Cereb Cortex 22:2076-2086. CrossRef Medline

Ashburner J (2007) A fast diffeomorphic image registration algorithm. Neuroimage 38:95-113. CrossRef Medline

Ashburner J, Friston KJ (2005) Unified segmentation. Neuroimage 26:839_ 851. CrossRef Medline

Carreiras M, Seghier ML, Baquero S, Estévez A, Lozano A, Devlin JT, Price CJ (2009) An anatomical signature for literacy. Nature 461:983-986. CrossRef Medline

Crinion JT, Green DW, Chung R, Ali N, Grogan A, Price GR, Mechelli A, Price CJ (2009) Neuroanatomical markers of speaking Chinese. Hum Brain Mapp 30:4108-4115. CrossRef Medline

Draganski B, Gaser C, Busch V, Schuierer G, Bogdahn U, May A (2004) Neuroplasticity: changes in grey matter induced by training. Nature 427 : 311-312. CrossRef Medline

Emmorey K, Allen JS, Bruss J, Schenker N, Damasio H (2003) A morphometric analysis of auditory brain regions in congenitally deaf adults. Proc Natl Acad Sci U S A 100:10049-10054. CrossRef Medline

Golestani N, Molko N, Dehaene S, LeBihan D, Pallier C (2007) Brain structure predicts the learning of foreign speech sounds. Cereb Cortex 17:575582. Medline

Golestani N, Price CJ, Scott SK (2011) Born with an ear for dialects? Structural plasticity in the expert phonetician brain. J Neurosci 31:4213-4220. CrossRef Medline

Jacquemot C, Pallier C, LeBihan D, Dehaene S, Dupoux E (2003) Phonological grammar shapes the auditory cortex: a functional magnetic resonance imaging study. J Neurosci 23:9541-9546. Medline

Kochunov P, Fox P, Lancaster J, Tan LH, Amunts K, Zilles K, Mazziotta J, Gao JH (2003) Localized morphological brain differences between Englishspeaking Caucasians and Chinese-speaking Asians: new evidence of anatomical plasticity. Neuroreport 14:961-964. CrossRef Medline

Lee H, Devlin JT, Shakeshaft C, Stewart LH, Brennan A, Glensman J, Pitcher K, Crinion J, Mechelli A, Frackowiak RS, Green DW, Price CJ (2007) Anatomical traces of vocabulary acquisition in the adolescent brain. J Neurosci 27:1184-1189. CrossRef Medline

Maguire EA, Gadian DG, Johnsrude IS, Good CD, Ashburner J, Frackowiak RS, Frith CD (2000) Navigation-related structural change in the hippocampi of taxi drivers. Proc Natl Acad Sci U S A 97:4398-4403. CrossRef Medline 
Maldjian JA, Laurienti PJ, Kraft RA, Burdette JH (2003) An automated method for neuroanatomic and cytoarchitectonic atlas-based interrogation of fMRI data sets. Neuroimage 19:1233-1239. CrossRef Medline

Mechelli A, Crinion JT, Noppeney U, O’Doherty J, Ashburner J, Frackowiak RS, Price CJ (2004) Neurolinguistics: structural plasticity in the bilingual brain. Nature 431:757. CrossRef Medline

Ono M, Kubik S, Abernathy CD (1990) Atlas of the cerebral sulci. Stuttgart: Thieme.

Penhune VB, Zatorre RJ, MacDonald JD, Evans AC (1996) Interhemispheric anatomical differences in human primary auditory cortex: probabilistic mapping and volume measurement from magnetic resonance scans. Cereb Cortex 6:661-672. CrossRef Medline

Rademacher J, Morosan P, Schormann T, Schleicher A, Werner C, Freund HJ, Zilles K (2001) Probabilistic mapping and volume measurement of human primary auditory cortex. Neuroimage 13:669-683. CrossRef Medline

Schneider P, Scherg M, Dosch HG, Specht HJ, Gutschalk A, Rupp A (2002) Morphology of Heschl's gyrus reflects enhanced activation in the auditory cortex of musicians. Nat Neurosci 5:688-694. CrossRef Medline

Schneider P, Andermann M, Wengenroth M, Goebel R, Flor H, Rupp A, Diesch E (2009) Reduced volume of Heschl's gyrus in tinnitus. Neuroimage 45:927-939. CrossRef Medline

Sutherland ME, Zatorre RJ, Watkins KE, Hervé PY, Leonard G, Pike BG, Witton C, Paus T (2012) Anatomical correlates of dynamic auditory processing: relationship to literacy during early adolescence. Neuroimage 60:1287-1295. CrossRef Medline

Wang Y, Xue G, Chen C, Xue F, Dong Q (2007) Neural bases of asymmetric language switching in second-language learners: an ER-fMRI study. Neuroimage 35:862-870. CrossRef Medline

Wong PC, Warrier CM, Penhune VB, Roy AK, Sadehh A, Parrish TB, Zatorre RJ (2008) Volume of left Heschl's gyrus and linguistic pitch learning. Cereb Cortex 18:828-836. Medline

Yoon U, Perusse D, Lee JM, Evans AC (2011) Genetic and environmental influences on structural variability of the brain in pediatric twin: deformation based morphometry. Neurosci Lett 493:8-13. CrossRef Medline 